\title{
Self-medication in Primary Dysmenorrhea among Medical and Nursing Undergraduate Students of a Tertiary Care Hospital: A Descriptive Cross-sectional Study
}

\author{
Jyoti Prabha Bharati, ${ }^{1}$ Sanjay Ulak, ${ }^{2}$ Merina Vaidya Shrestha, ${ }^{3}$ Sanjaya Mani Dixit, ${ }^{1}$ Anna Acharya, ${ }^{1}$ \\ Ashish Bhattarai ${ }^{1}$ \\ 'Department of Pharmacology, Kathmandu Medical College Teaching Hospital, Duwakot, Bhaktapur, Nepal, \\ ${ }^{2}$ Department of Paediatrics, Bhaktapur Hospital, Bhaktapur, Nepal, ${ }^{3}$ Department of Community medicine, \\ Kathmandu Medical College Teaching Hospital, Duwakot, Bhaktapur, Nepal.
}

\section{ABSTRACT}

Introduction: Primary dysmenorrhea is one of the most common gynecological problems among adolescent females. It is defined as painful menses in women with normal pelvic anatomy, usually beginning during adolescence. This study aims to find out prevalence of self-medication practice in primary dysmenorrhea among medical and nursing undergraduate students.

Methods: A descriptive cross-sectional study was conducted in a tertiary care hospital from November 2020 to March 2021 after taking ethical approval from the Institutional Review Committee. Convenient sampling technique was used. A total of 269 female medical and nursing students with complaints of dysmenorrhea were enrolled and the remedial methods used by them such as self-medication, medical advice and home remedies for dysmenorrhea were asked using an online questionnaire delivered to participants. Data analysis was done in the Statistical Package of Social Sciences. Point estimate at 95\% Confidence Interval was calculated along with frequency and proportion for binary data.

Results: Self-medication practice for dysmenorrhea was reported in $175(65 \%)$ of students. The prevalence of mild or moderate pain was commonly present in age group 21-25 years. commonly used for self-medication was mefenamic acid $121(48 \%)$, followed by ibuprofen $51(20.3 \%)$ and paracetamol $41(16.3 \%)$.

Conclusions: Self- medication practice among medical and nursing undergraduate students is high despite awareness of adverse effects.

Keywords: awareness; dysmenorrhea; menstrual cycle; self-medications.

\section{INTRODUCTION}

Primary dysmenorrhea is defined as "painful menses in women with normal pelvic anatomy, usually beginning during adolescence characterized by crampy pelvic pain shortly before or at the onset of menses lasting for 1 to 3 days". ${ }^{1}$ Painful uterine contractions and discomfort occur during these cycles mainly felt in lower abdomen but may radiate to back and the thigh. ${ }^{2,3}$ There are primary Dysmenorrhea without pathology and secondary to pelvic pathology. ${ }^{4}$

Use of medicines by the patient either on their own or on the advice of pharmacists without consulting registered health practitioners is self-medication. ${ }^{5}$ Due to easy accessibility, self-medication for primary dysmenorrhea is very common nowadays. ${ }^{6}$

Hence, this study is taken up to evaluate self-medication practice in primary dysmenorrhea among medical and nursing undergraduate students.

Correspondence: Dr. Jyoti Prabha Bharati, Department of Pharmacology, Kathmandu Medical College Teaching Hospital, Duwakot, Bhaktapur, Nepal. Email: jtbharati@gmail.com, Phone: 977-9844874606. 
The main objective of this study is to find out the prevalence of self-medication among medical and nursing undergraduate students.

\section{METHODS}

A descriptive cross-sectional study was done in medical and nursing undergraduate students of Kathmandu Medical College from November 2020 to March 2021. Ethical clearance (Ref: 2011202002) was obtained from the Institutional Review Committee of Kathmandu Medical College before the start of the study. Convenient sampling technique was used. The questionnaire did not contain any identifying details of the students and confidentiality was strictly maintained throughout the study. The participant's consent to participate in the study was implied when they clicked on the next button to answer the questionnaire and they had complete freedom either to decline or answer the questionnaire.

All medical and nursing under-graduate students willing to give consent were included in the study. Students having secondary dysmenorrhea (painful menstruation associated with underlying pathology) were excluded from the study.

Sample size was calculated as:

$$
\begin{aligned}
\mathrm{n} & =\mathrm{Z}^{2} \times \mathrm{p} \times \mathrm{q} / \mathrm{e}^{2} \\
& =(1.96)^{2} \times 0.796 \times 0.204 /(0.05)^{2} \\
& =250
\end{aligned}
$$

Where,

$\mathrm{n}=$ Sample size

$z=1.96$ at $95 \% \mathrm{Cl}$

$\mathrm{p}=$ prevalence of self-medication practice in primary dysmenorrhea among medical student $(79.6 \%)^{7}$

$q=1-p$

$\mathrm{e}=$ margin of error, $5 \%$

The sample size is estimated to be 250 at $95 \%$ confidence interval. Adding $10 \%$ of non-response rate, the total sample size is 269 .

The data was collected from online questionnaires delivered to participants via email, Viber, WhatsApp, messenger, etc because of COVID-19 pandemic. The data collection included demographic information, regularity of menstrual cycle, duration of menstrual discomfort, symptoms of primary dysmenorrhea, severity of pain assessment, self-medication used to relieve pain and awareness of self-medication. Pain assessment was done using a Visual Analogue Scale (VAS).

Responses from the Google form were downloaded in excel sheet format. Invalid data with invalid response was cleared and coding for responses was done. Data analysis was done in the Statistical Package of Social
Sciences. Point estimate at 95\% Confidence Interval was calculated along with frequency and proportion for binary data.

\section{RESULTS}

Out of 269 students, 175 (65\%) have taken selfmedication and only $20(7.43 \%)$ visited registered healthcare practitioners which shows a high prevalence of self-medication among students (Figure 1).

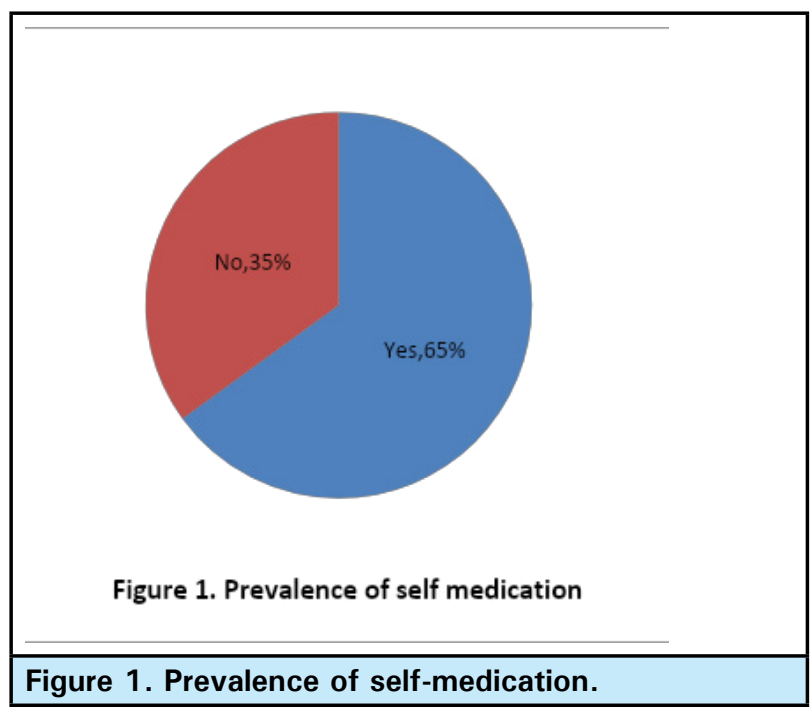

Among various drugs used for self-medication, mefenamic acid tops the list with $121(48 \%)$ followed by ibuprofen 51 (20.3\%) and paracetamol 41 (16.3\%). Majority of them were aware of the negative impacts of self-medication 190 (70.6\%) (Table 1).

\begin{tabular}{|lc|}
\hline \multicolumn{2}{|l|}{ Table 1. Prevalence of self-medication among students } \\
and most preferred medicines used in practice. \\
\hline Variables & $\mathbf{n}(\%)$ \\
\hline Self-medication among different stream \\
Medical & $141(80.57)$ \\
Nursing & $34(19.43)$ \\
Preferred medicines & $121(48)$ \\
Mefenamic acid & $51(20.3)$ \\
lbuprofen & $41(16.0)$ \\
Paracetamol & $15(6.0)$ \\
Mefenamic acid+dicyclomine & $12(4.8)$ \\
Diclofenac & $11(4.3)$ \\
Other & $190(70.6)$ \\
Aware of negative impact of self-medication \\
Yes & $79(29.36)$ \\
No & \\
Outcome of self-medication & $109(62.28)$ \\
Cured & $41(23.42)$ \\
Improved & $25(14.28)$ \\
No improvement &
\end{tabular}

Besides self-medication other self-care strategies of pain relief common among the students were 200 
Bharati et al. Self-medication in Primary Dysmenorrhea among Medical and Nursing Undergraduate Students of a Tertiary Care Hospital...

(74.43\%) hot bath/bag, 234 (86.98\%) rest, 114 (42.37\%) reduced physical activities, $68(25.27 \%)$ massage, 58 $(21.56 \%)$ herbal remedy and $47(17.47 \%)$ yoga.

Among 269 students, 192 (71.4\%) were medical and $77(28.6 \%)$ were nursing. Participants' age ranged between 17 to 28 years, and the mean age was $20.88 \pm$ 1.51 years (Table 2 ).

\begin{tabular}{|ll|}
\hline \multicolumn{2}{|l|}{$\begin{array}{l}\text { Table 2. Characteristics of menstrual cycle in } \\
\text { participants with dysmenorrhea. }\end{array}$} \\
\hline $\begin{array}{l}\text { Variables } \\
\text { Regular menstrual cycle }\end{array}$ \\
Regular & $195(72.5)$ \\
Irregular & $74(27.5)$ \\
Duration of Menstrual cycle & \\
2-3 days & $21(71.8)$ \\
$3-4$ days & $1(0.4)$ \\
$4-5$ days & $191(71)$ \\
$>5$ days & $56(20.8)$ \\
Amount of menstrual flow & \\
Scanty & $58(21.6)$ \\
Moderate & $190(70.6)$ \\
Heavy & $21(7.8)$ \\
\hline
\end{tabular}

\begin{tabular}{|ll|}
\hline Interval & \\
$<28$ days & $35(13)$ \\
$28-30$ & $155(57.6)$ \\
$>30$ days & $79(29.4)$ \\
Menstrual discomfort & \\
During menstrual period & $43(16)$ \\
During first 2 days & $189(70)$ \\
Throughout the cycle & $37(13)$ \\
Symptoms & \\
Nausea & $83(7.2)$ \\
Vomiting & $27(2.4)$ \\
Abdominal pain & $182(15.9)$ \\
Headache & $73(6.4)$ \\
Diarrhea & $50(4.4)$ \\
Back pain & $187(16.3)$ \\
Myalgia & $133(9.8)$ \\
Cramps & $184(16)$ \\
Loss of appetite & $92(8)$ \\
Irritability & $157(13.7)$ \\
\hline
\end{tabular}

The assessment of pain experienced by students according to different age groups and streams showed most of them experienced mild or moderate pain. The prevalence of mild or moderate pain was most common in the age group 21-25 years (Table 3 ).

\begin{tabular}{|c|c|c|c|c|c|}
\hline Variables & Mild n (\%) & moderate $\mathrm{n}(\%)$ & Severe $\mathrm{n}(\%)$ & Very severe $n(\%)$ & Worst $\mathrm{n}(\%)$ \\
\hline \multicolumn{6}{|l|}{ Age } \\
\hline $15-20$ & $37(32.6 \%)$ & $33(28.9 \%)$ & $20(17.5 \%)$ & $17(14.9 \%)$ & $7(6.1 \%)$ \\
\hline $21-25$ & $41(27 \%)$ & $45(29.6 \%)$ & $20(13.2 \%)$ & $23(15.1 \%)$ & $23(15.1 \%)$ \\
\hline $26-30$ & - & $1(33.3 \%)$ & - & $2(66.7 \%)$ & - \\
\hline \multicolumn{6}{|l|}{ stream } \\
\hline Medical & $43(12.4 \%)$ & $52(27.1 \%)$ & $33(17.2 \%)$ & $34(17.7 \%)$ & $30(15.6 \%)$ \\
\hline Nursing & $35(45.5 \%)$ & $27(35.1 \%)$ & $7(9.1 \%)$ & $8(10.4 \%)$ & - \\
\hline
\end{tabular}

\section{DISCUSSION}

In the present study, the mean age of students was $20.88 \pm 1.51$ years which was more or less similar to Anand S et al. ${ }^{8} 195$ (72.5\%) participants had regular menstrual cycle which was similar to the study done in India by Jayanthi B et al. ${ }^{9}$ Among 269 participants who experienced dysmenorrhea, 191 (71\%) of the participants reported 4-5 days of menstrual cycle and $189(70 \%)$ reported pain for first 2 days of menstrual flow which was similar to Banikarim $\mathrm{C}$ et al. and Fatima A et al. ${ }^{10,11}$

Assessment of pain intensity and duration revealed that female undergraduates experience mild, moderate, severe, very severe and worst pain during menstruation which was similarly explained in the study done in China by Chen ${ }^{12}$ and Nigeria by Emmanuel et al. ${ }^{13}$
Most females in this survey experienced mild or moderate pain in the age group 21-25 years. The differences in the pain severity may be related to individual differences in pain perception and variability in pain threshold.

Majority of students 175 (65\%) were taking selfmedication, only very few of them visited registered healthcare practitioners $20(7.43 \%)$ which shows a high prevalence of self-medication among students. Among various drugs used for self-medication, mefenamic acid tops the list with 121 (48\%) which is similar to the study done by Marjoribanks $\mathrm{J}$ et al. ${ }^{14}$ and Feng $X$ et al. ${ }^{15}$ mefenamic acid, being the widely used and preferred drug in primary dysmenorrhea. In contrast to our finding, study done by Farnandez et al. ${ }^{16}$ in Spain, most of the students used paracetamol as a common pain reliever. We also found that beside medicines students practised rest/relaxation, hot bath/ bag, herbal/home remedies, reduced physical activities 
and yoga for managing menstrual pain, similar to study of Anand S et al. ${ }^{8}$

Most of the students were aware of the negative impacts of self-medication $190(70.6 \%)$ but only few opted for medical consultation. According to the students, reasons for not consulting were emergency use, prior experience in medicine, mild nature of illness, cost saving, lack of time to visit health care facilities and ease of access to non-prescribed medication. Most of the drugs were purchased from pharmacies (64.31\%) rather than after visiting registered health care practitioners. One way to control this practice is by keeping check on buying and selling of unprescribed medicines with measures like educating pharmacists, formulating strict laws etc. Other important way is to educate students about self-medication and its consequences by lectures, seminars, and inclusion of topic in the curriculum itself. Alongside above steps, discussion on the topic among students, counselling by seniors or even faculty staff that not only make them aware but also encourage to bring change in behaviour also need to be exercised for tangible results.

\section{CONCLUSIONS}

In primary dysmenorrhoea, self-medication practice among medical and nursing undergraduate students is excessive despite high awareness of adverse effects. So, along with strict laws and various awareness programmes beginning early at school college levels, measures to bring change in behavior should also be emphasised.

\section{ACKNOWLEDGEMENTS}

Authors would like to thank all the participants who were involved in the study.

\section{Conflict of Interest: None.}

\section{REFERENCES}

1. Adeyemi A, Adekanle D. Management Of Dysmenorrrhoea Among Medical Students. The Internet Journal of Gynecology and Obstetrics. 2006;7(1):1-6. [․ㅏll Text]

2. Ezeukwu AO, Elochukwu PU, Ojukwu CP. Self-reported pain relief strategies for primary dysmenorrhea used by Nigerian female undergraduates. Int J Recent Sci Res. 2014 Jan;5(1):261-65. [․ㅏll Text]

3. Barrett KE, Barman SM, Brooks HL, X. J, Yuan J. Ganong's Review of Medical Physiology. 26th ed. New York: McGraw Hill Medical; 2019. p.752 [Full Text]

4. Fraser D, Cooper M. Myles' Textbook for Midwives. 15th ed. Amsterdam: Elsevier; 2009. p1148. [Full Text]

5. Stephen S, Sukanya M, Scaria T, Sunny TT, Shettigar D. Self-medication practices among undergraduate nursing students in South India: A cross sectional study. Am Int J Res Sci Technol Eng Math. 2013;2(3):159-62. [Full Text]

6. Sugumar R, Krishnaiah V, Channaveera GS, Mruthyunjaya S. Comparison of the pattern, efficacy, and tolerability of self-medicated drugs in primary dysmenorrhea: a questionnaire based survey. Indian J Pharmacol. 2013 Mar-Apr;45(2):180-3. [라Med | Full Text | DOI]

7. Sunitha S, Dharman D, Manohar D, Daran SS, Vinod VA, Roy A. The self-medication practice in primary dysmenorrhea among pharmacy students-a cross-sectional questionnaire study. Int J Res Hosp Clin Pharm. 2019 Sep 30;1(4):97-100. [ull Text $\mid$ DOI]

8. Anand S, Akhtar T, Bhuvana K. A study of pattern of self-medication among students for dysmenorrhea. Asian J Pharm Clin Res. 2018;11(6):436-8. [Full Text | DOI]
9. Jayanthi B., Anuradha H. V. Comparison of self-medication practice for dysmenorrhoea in medical, nursing and dental students. Int J Basic Clin Pharmacol. 2016 Apr;5(2):269-73. [Full Text $\mid \underline{\text { DOI] }}$

10. Banikarim C, Chacko MR, Kelder SH. Prevalence and impact of dysmenorrhea on Hispanic female adolescents. Arch Pediatr Adolesc Med. 2000 Dec;154(12):1226-9. [PubMed | Full Text | DOI]

11. Fatima A, Mamatha KR, Ambika B, Rajarathna K. Self-medication practice in primary dysmenorrhea among medical and paramedical students: A cross-sectional questionnaire study. Natl J Physiol Pharm Pharmacol. 2017;7(5):458-63. [Full Text | DOI]

12. Chen L, Tang L, Guo S, Kaminga AC, Xu H. Primary dysmenorrhea and self-care strategies among Chinese college girls: a cross-sectional study. BMJ Open. 2019 Sep 18;9(9):e026813. [uuMed | Full Text | DOI]

13. Emmanuel A, Achema G, Gimba SM, Mafuyai MJ, Afoi BB, Ifere I O. Management of dysmenorrhoea among undergraduates in Nigeria. Int $\mathrm{J}$ Med Biomed Res 2013;2(2):142-6. [Full Text | DOI]

14. Marjoribanks J, Proctor M, Farquhar C, Derks RS. Nonsteroidal anti-inflammatory drugs for dysmenorrhoea. Cochrane Database Syst Rev. 2010 Jan 20; (1): CD001751. [Full Text | DOI]

15. Feng $X$, Wang $X$. Comparison of the efficacy and safety of non-steroidal anti-inflammatory drugs for patients with primary dysmenorrhea: A network meta-analysis. Mol Pain. 2018;14:1744806918770320. [Full Text | DOI] 
16. Parra-Fernández ML, Onieva-Zafra MD, Abreu-Sánchez A, Ramos-Pichardo JD, Iglesias-López MT, Fernández-Martínez E. Management of Primary Dysmenorrhea among University Students in the South of Spain and Family Influence. Int J Environ Res Public Health. 2020 Aug 1;17(15):5570. [PubMed | Full Text | DOI]

This work is licensed under a Creative Commons Attribution 4.0 International License. The images or other third party material in this article are included in the article's Creative Commons license, unless indicated otherwise in the credit line; if the material is not included under the Creative Commons license, users will need to obtain permission from the license holder to reproduce the material. To view a copy of this license, visit http://creativecommons.org/licenses/by/4.0/ 